\title{
Clinical Nursing Recommendations for the Treatment of the BTX-A Injections Due to Neurological Detrusor Overactivity
}

\author{
J. M. Lin ${ }^{1,2}$, Hui Chen ${ }^{1}$, M. P. Huang1, Q. L. Liu' ${ }^{1}$, Q. Q. Li ${ }^{1}$, T. H. Huang1 , X. Y. Yang1 \\ ${ }^{1}$ Department of Urology, Guangdong Provincial Work Injury Rehabilitation Hospital, Guangdong, China \\ ${ }^{2}$ Departments of Emergency, The Eighth Hospital of Guangzhou, Guangdong, China \\ Email: *doc.chenhui @163.com
}

How to cite this paper: Lin, J.M., Chen, H., Huang, M.P., Liu, Q.L., Li, Q.Q., Huang, T.H. and Yang, X.Y. (2019) Clinical Nursing Recommendations for the Treatment of the BTX-A Injections Due to Neurological Detrusor Overactivity. Open Journal of Urology, 9, 102-105.

https://doi.org/10.4236/oju.2019.96012

Received: January 26, 2019

Accepted: June 27, 2019

Published: June 30, 2019

Copyright $\odot 2019$ by author(s) and Scientific Research Publishing Inc. This work is licensed under the Creative Commons Attribution International License (CC BY 4.0).

http://creativecommons.org/licenses/by/4.0/

(C) (i) Open Access

\begin{abstract}
Background: Neurological detrusor overactivity (NDO) is commonly associated with various neurogenic diseases. Botulinum toxin A (BTX-A) has been proposed as alternatives to traditional treatments. Objective: To summarize the clinical experience of nursing care for the treatment of the Botulinum toxin A (BTX-A) injections due to neurological detrusor overactivity (NDO). Methods: We reviewed the data of 32 inpatients who received BTX-A injections between August 2014 to July 2016. Their mean age was 27.4 years old (range: 19 - 38). They were all on clean intermittent catheterization. All patients presented detrusor overactivity resistant to oral anticholinergic treatment. Results: There were significant difference between outcomes at baseline and week12 for $\mathrm{P}_{\text {detmax }}\left(60.08 \mathrm{cmH}_{2} \mathrm{O}\right.$ vs. $\left.28.04 \mathrm{cmH}_{2} \mathrm{O}, \mathrm{P}<0.001\right)$, $\mathrm{V}_{\mathrm{FIDC}}(165.55 \mathrm{ml}$ vs. $276.07, \mathrm{P}<0.001)$, and urinary incontinence respectively. Prompt psychological counseling and nursing help reduce the patients' passive psychology, enhance their confidence with good postoperative recovery and symptoms improvement. Conclusions: Patients were satisfied with the treatment and nursing by targeted perioperative nursing.
\end{abstract}

\section{Keywords}

Botulinum Toxin A, Neurological Detrusor Overactivity, Nursing Care

\section{Introduction}

Neurological detrusor overactivity (NDO) is characterized by spontaneous or provoked involuntary detrusor contractions during storage phase in urodynamic investigation which caused by various neurogenic diseases such as Parkinson's disease, stroke and spinal cord injury [1] [2]. NDO can cause urinary inconti- 
nence, hydronephrosis, recurrent urinary tract infection, vesicoureteric reflux (VUR); the most dangerous being damage of renal function [3]. Botulinum toxin A (BTX-A) is a neuromuscular blocking agent indicated by the beneficial treatment effect on NDO patients who have an inadequate response to or are intolerant to anticholinergic medication [4]. Therefore, encouraged by our satisfactory clinical effects, we summarized our perioperative nursing experience for BTX-A injection.

\section{Materials and Methods}

A retrospective data analysis was performed. Patients who received BTX-A injections between August 2014 to July 2016, were analyzed. Characteristics in terms of gender, age, weight, time since SCI, neurological injury level, American Spinal Injury Association Impairment Scale were assessed. Inclusion criteria were: 1) at least 18 years old with urinary incontinence secondary to various neurogenic disorders; 2) urodynamics; 3 ) an inadequate response to oral anticholinergics or discontinued anticholinergics due to adverse events; 4) patients or their family caregiver skilled in clean intermittent catheterization (CIC). All patients provided written informed consent, and the local institutional review board at each center approved the protocol.

Injections were performed with no anesthesia or under epidural anesthesia in the operating room with a $21 \mathrm{~F}$ rigid cystoscope. The bladder was instilled with $100-150 \mathrm{ml}$ sterile saline to achieve adequate visualization so as to avoid the blood vessels during injections. A 23 gauge needle (Cook Urological Incorporated) was inserted approximately $2 \mathrm{~mm}$ into the detrusor. $200 \mathrm{U}$ Botox ${ }^{\circledR}$ vials (100 $\mathrm{U}$ each) were reconstituted in a total of $30 \mathrm{ml}$ sterile saline $(6.7 \mathrm{U} / \mathrm{ml})$. A total of 30 injections of $1 \mathrm{ml}$ each were administered, evenly distributed about 1 $\mathrm{cm}$ apart across the bladder wall [5]. A 16 Foley catheter had been inserted for 3 - 5 days. Comprehensive perioperative nursing was provided for patients with NDO prepared to accept detrusor botulinum toxin type A injection, by the means of in-depth observation, timely detection and reasonable solution to the clinical nursing issues.

Related adverse events were recorded. Statistical analysis was performed using the SPSS 13.0 soft-ware package (SPSS, Inc., Chicago, IL). Statistical relationships between pre- and postoperative outcome parameters were sought by the Student's t-test for quantitative variables. Statistical significance was considered at $\mathrm{P}$ value $<0.05$.

\section{Results}

The records of 73 consecutive patients, who presented to the botulinum toxin consultation from August 2014 to July 2016, were analyzed. From these, 32 inpatients were treated with BTX-A for NDO.

The mean age was 27.4 years old (19 - 38 years). They were all on clean intermittent catheterization. Table 1 lists the baseline characteristics. 
Table 1. Baseline patients characteristics.

\begin{tabular}{|c|c|}
\hline Parameter & Number of patients $(n=32)$ \\
\hline Age $^{*}, y r$ & $27.4(19-38)$ \\
\hline Gender, female ${ }^{* *}$ & $17(53.12)$ \\
\hline Weight* ${ }^{\star} \mathrm{kg}$ & $57.28(49-78)$ \\
\hline Time since $\mathrm{SCI}^{*}$, months & $11.66(9-19)$ \\
\hline $\begin{array}{l}\text { Neurological injury level** } \\
\text { C6-C8/T1-T12/L1-L5 }\end{array}$ & $0 / 29(70.73) / 12(29.27)$ \\
\hline $\mathrm{AIS}^{* *}, \mathrm{~A} / \mathrm{B} / \mathrm{C}$ & $29(70.73) / 11(26.83) / 1(2.44)$ \\
\hline Anticholinergic drugs use prior to treatment ${ }^{* *}$ & $32(100)$ \\
\hline CIC prior to treatment** & $32(100)$ \\
\hline
\end{tabular}

Abbreviations: $\mathrm{SCI}=$ spinal cord injury; AIS = American Spinal Injury Association Impairment Scale; CIC $=$ clean intermittent catheterization. ${ }^{*}$ Values are given as mean \pm standard deviation; ${ }^{* *}$ Values are given as $\mathrm{n}(\%)$.

Table 2. Outcomes at baseline and week 12.

\begin{tabular}{cccc}
\hline Outcome & Baseline & Week 12 & P Value \\
\hline $\mathrm{P}_{\text {detmax }}, \mathrm{cmH}_{2} \mathrm{O}$ & $60.08 \pm 17.02$ & $28.04 \pm 8.74$ & $<0.001$ \\
$\mathrm{~V}_{\mathrm{FIDC}}, \mathrm{ml}$ & $165.55 \pm 41.96$ & $276.07 \pm 68.33$ & $<0.001$ \\
Urinary incontinence episodes, $\mathrm{n} / \mathrm{d}$ & $7.38 \pm 2.64$ & $2.06 \pm 0.62$ & $<0.001$ \\
\hline
\end{tabular}

$\mathrm{P}_{\text {detmax }}=$ maximum detrusor pressure during first involuntary detrusor contraction; $\mathrm{V}_{\mathrm{FIDC}}=$ volume at first involuntary detrusor contraction.

Table 2 shows that significant difference between outcomes at baseline and week 12 for $\mathrm{P}_{\text {detmax }}\left(60.08 \mathrm{cmH}_{2} \mathrm{O}\right.$ vs. $\left.28.04 \mathrm{cmH}_{2} \mathrm{O}, \mathrm{P}<0.001\right), \mathrm{V}_{\mathrm{FIDC}}(165.55 \mathrm{ml}$ vs. $276.07, \mathrm{P}<0.001)$, and urinary incontinence respectively.

\section{Discussion}

The primary aim in the treatment of NDO is to ensure that the detrusor pressure remains within safe limits during both the filling phase and the voiding phase for protection of the upper urinary tract [6]. The present trial reports significant improvements in these parameters were evident with the 200-U dose of BTX-A injection [6]. Besides, the improvements in urodynamic outcomes also transfer to the increases in scores of the patient's quality of life.

Undoubtedly, our prompt nursing care also played an important role in this significant clinical improvement. Timely psychological counseling and nursing significantly improve the patients' negative psychology, enhanced their confidence with good postoperative recovery and symptoms improvement. During the preoperative period, we paid close attention to psychological condition and help patients reduce anxiety. Postoperative care included observation of related adverse events. Oral prophylactic antibiotics (except aminoglycosides) were administered on the day of treatment. The most important in nursing was to keep the catheter unobstructed and prevent and treat the infection. Patients received 
bladder irrigation with normal saline with the aim of preventing blockage resulted from continuing hematuria. After removal of catheter, patients kept on clean intermittent catheterization.

A limitation of this study is that the number of patients was relatively fewer. Therefore, further studies are warranted.

\section{Conclusions}

Our results have demonstrated that Patients were satisfied with the treatment and nursing by targeted perioperative nursing.

\section{Acknowledgements}

This study was supported by Medical Scientific Research Foundation of Guangdong Province, China (grant number B2017040, A2018124).

\section{Conflicts of Interest}

The authors declare no conflicts of interest regarding the publication of this paper.

\section{References}

[1] Abrams, P., Cardozo, L., Fall, M., Griffiths, D., Rosier, P., Ulmsten, U., et al. (2002) The Standardisation of Terminology of Lower Urinary Tract Function: Report from the Standardisation Sub-Committee of the International Continence Society. Neurourology and Urodynamics, 21, 167-178. https://doi.org/10.1002/nau.10052

[2] Hagen, E.M., Eide, G.E., Rekand, T., Gilhus, N.E. and Gronning, M. (2010) Traumatic Spinal Cord Injury and Concomitant Brain Injury: A Cohort Study. Acta Neurologica Scandinavica, 122, 51-57. https://doi.org/10.1111/j.1600-0404.2010.01376.x

[3] Denys, P., Corcos, J., Everaert, K., Chartier-Kastler, E., Fowler, C., et al. (2006) Improving the Global Management of the Neurogenic Bladder Patient: Part I. The Complexity of Patients. Current Medical Research and Opinion, 22, 359-365. https://doi.org/10.1185/030079906X89702

[4] Chapple, C. and Patel, A. (2006) Botulinum Toxin: New Mechanisms, New Therapeutic Directions? European Urology, 49, 606-608. https://doi.org/10.1016/j.eururo.2006.01.005

[5] Schurch, B., Stöhrer, M., Kramer, G., Schmid, D.M., Gaul, G. and Hauri, D. (2000) Botulinum-A Toxin for Treating Detrusor Hyperreflexia in Spinal Cord Injured Patients: A New Alternative to Anticholinergic Drugs? Preliminary Results. Journal of Urology, 164, 692-697. https://doi.org/10.1016/S0022-5347(05)67283-7

[6] Stöhrer, M., Blok, B., Castro-Diaz, D., Chartier-Kastler, E., Del Popolo, G., Kramer, G., et al. (2009) EAU Guidelines on Neurogenic Lower Urinary Tract Dysfunction. European Urology, 56, 81-88. https://doi.org/10.1016/j.eururo.2009.04.028 